\title{
Neodymia-silica nanocomposites: Synthesis and structural properties
}

\section{Saruchi $^{\star}$, Surbhi, Praveen Aghamkar, Sushil Kumar}

Materials Science Lab, Department of Physics, Chaudhary Devi Lal University, Sirsa 12 055, Haryana, India

*Corresponding author. Tel: (+91) 9466691408; Fax: (+91) 1666-239835; E-mail: saruchi.science@ gmail.com

\section{ABSTRACT}

Nanomaterials and nanostructures have received steadily growing interests as a result of their peculiar and fascinating properties and applications. Neodymia-silica nanocomposites were prepared by sol-gel route followed by calcination. The samples were prepared with different concentration of dopant $\left(\mathrm{Nd}_{2} \mathrm{O}_{3}\right)$ and calcined in a programmable furnace at $1000{ }^{\circ} \mathrm{C}$ for $5 \mathrm{~h}$. The structural evolution of samples was investigated by employing techniques such as XRD, FTIR and TEM. X-ray diffraction patterns showed that the samples were nanocrystalline and the size of crystallites has been determined using Debye-Scherrer relation. The FTIR spectra confirmed the presence of functional groups of prepared material. The particle size of samples was also estimated through TEM analysis. It has been observed that crystallinity as well as particle size of the samples increases with increase in dopant concentration.Copyright $\odot 2013$ VBRI press.

Keywords: Nanocomposite; neodymia; silica; sol-gel route; XRD; FTIR; TEM.

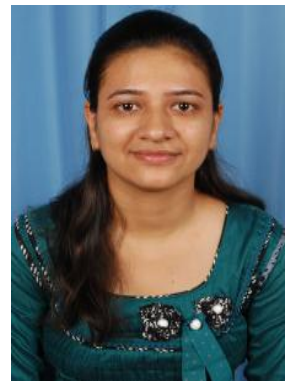

Saruchi is presently pursuing research leading to $\mathrm{Ph} . \mathrm{D}$. degree in the area of Materials Science which specifically deals with "Studies on sol-gel derived nanodimentional metal oxides and their binaries" from Chaudhary Devi Lal University, Sirsa, Haryana. Previously she had done M.Phil. (gold medalist) and M.Sc. (second position) in Physics from the same university. She completed her M.Phil. project on the topic entitled "Structural characterization of $\mathrm{Nd}$ doped silica".

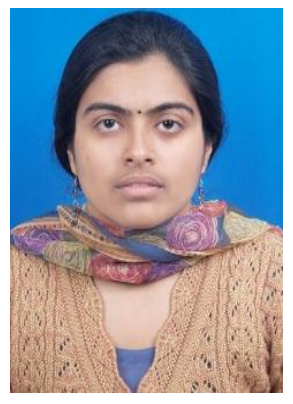

Surbhi is a science scholar currently pursuing research leading to Ph.D. degree on "Investigations on nanoscale metal oxides and their binary systems synthesized by sol-gel technique. She completed her M. Phil. Physics from Chaudhary Devi Lal University, Sirsa, Haryana, post graduate in Physics from Banasthali Vidyapeeth, Rajasthan and graduation in Electronics from Kurukshetra University, Haryana. During studies, she has carried out projects such as "Device modeling implementation of MEXTRAM using MATLAB", "Synthesis of Nd-doped silica matrix" and she got training in "Fiber optics" at Central Scientific Instruments Organization, Chandigarh.

\section{Introduction}

Rare earth (RE) doped glasses are an important class of materials due to their many scientific and technological applications in many fields such as miniaturized optical devices, catalysts, [1-4] photonics, [5] advanced high temperature superconductors/ceramics [6] and integrated optics [7]. They can also be employed effectively as active media for glass lasers [8-9]. It is well known that the local structure around rare earth ion in glasses defines the properties of the laser emission when these materials are used as an active medium for solid-state lasers. In traditional oxide glasses such as borate, silicate and phosphate, the RE ions can locate in a vacancy of the structure acting as a network modifier [10-12]. Depending on the concentration, they can change the glasses network affecting both the emission and thermo-mechanical properties.

Rare earth ions are used as dopants in glasses due to their well-defined and sharp energy levels, which may serve as structural probes for the environment of the dopants. Over past two decades, since the observation of lasing in Nd-doped silica by Snitzer, [13] there have been much research and development efforts on silica glass lasers doped by neodymium. They possess many properties suitable for high power laser applications. These include low thermal expansion co-efficient, high temperature stability and low nonlinear refractive index.

Several techniques such as melt casting, [14] chemical vapour deposition [15] and sol-gel [16] have been 
attempted to synthesize neodymium doped silica glass. The studies were concerned with different steps like glass formation, including solution preparation, gel processing, gel drying, heating procedure and high temperature glass sintering. Sol-gel process is of low temperature nature[1724] and holds the possibility of greater homogeneity on a molecular scale. Sol-gel process matches the demands of industries in terms of bulk preparation of materials with high density, high mechanical strength and high shock resistance, high specific area, compositional purity and optical grade quality [25].

In the present work, neodymia-silica nanocomposites were prepared by sol-gel route. We investigated the changes in structure and microstructure of silica glasses with various dopant concentrations. The structure of samples was characterized by FTIR and XRD; while the microstructure of samples was studied by TEM.

\section{Experimental}

Synthesis

Tetraethylorthosilicate (TEOS, Aldrich 99.999\%), Ethyl alcohol $\left(\mathrm{C}_{2} \mathrm{H}_{5} \mathrm{OH}\right.$, Aldrich $\left.99.9995 \%\right)$, Hydrochloric acid ( $\mathrm{HCl}$, Aldrich 99.995\%), Neodymium oxide $\left(\mathrm{Nd}_{2} \mathrm{O}_{3}\right.$, Aldrich $99.99 \%)$, Nitric acid $\left(\mathrm{HNO}_{3}\right.$, Aldrich $\left.99.5 \%\right)$ and deionized water were used for the preparation of samples. All these chemicals were of analytical grade and used as received. Binary oxides were prepared by sol-gel route. Initially, we prepared two solutions. In the first solution, $\mathrm{H}_{2} \mathrm{O}, \mathrm{C}_{2} \mathrm{H}_{5} \mathrm{OH}$, TEOS, $\mathrm{HCl}$ have been taken in appropriate amounts and mixed properly using magnetic stirrer. In the second solution, Neodymium was introduced in the initial stage of the process, by dissolving $1.02 \mathrm{~g}$ of $\mathrm{Nd}_{2} \mathrm{O}_{3}$ in suitable amount of $\mathrm{HNO}_{3}$ and stirred. After that, this solution was mixed in the silica sol solution prepared before and stirred rigorously. The same procedure has been followed to prepare the second sample with the amount of $\mathrm{Nd}_{2} \mathrm{O}_{3}$ as $1.7 \mathrm{~g}$. The resultant solution was stirred at 1000 rpm for $3 \mathrm{~h}$ to make it homogeneous. The $\mathrm{pH}$ of the solution was 5 approximately. It was observed that the gelation starts after 4 days approximately. After gelation, the samples were kept inside an oven at room temperature for 21 days for aging which results in further shrinkage and stiffening of the gel until no shrinkage appears. After that, the samples were dried in an oven at $120{ }^{\circ} \mathrm{C}$ for $3 \mathrm{~h}$. Densification of the prepared glass samples were obtained by annealing them in air for $5 \mathrm{~h}$ at $1000{ }^{\circ} \mathrm{C}$ in a muffle furnace with heating rate of $10^{\circ} \mathrm{C} / \mathrm{min}$. The prepared samples were finely powdered using mortar and pestle for characterization.

\section{Characterization}

Several complementary methods were used to characterize the prepared samples like X-ray Diffraction (XRD), Fourier Transform Infrared spectroscopy (FTIR) and Transmission Electron Microscopy (TEM). The XRD patterns of the prepared samples were recorded with X-ray diffractometer (X' Pert-Philips) with monochromatic $\mathrm{CuK}_{\boldsymbol{\alpha}}$ radiation of wavelength $1.5406 \mathrm{~A}^{\circ}$ with $\mathrm{Ni}$ filter. The FTIR study of samples was performed with FTIR spectrophotometer
(Perkin Elmer 1600) in the wave number range of 4000$500 \mathrm{~cm}^{-1}$. Specimens for FTIR study were prepared in the form of pallets by pressing the homogeneous mixture of powder sample and $\mathrm{KBr}$. The microstructure of prepared samples was evaluated using Transmission Electron Microscope. Specimens for TEM study were prepared by dispersing a small amount of powdered sample in ethanol and putting a droplet of the suspension on a cooper grid coated with perforated carbon.

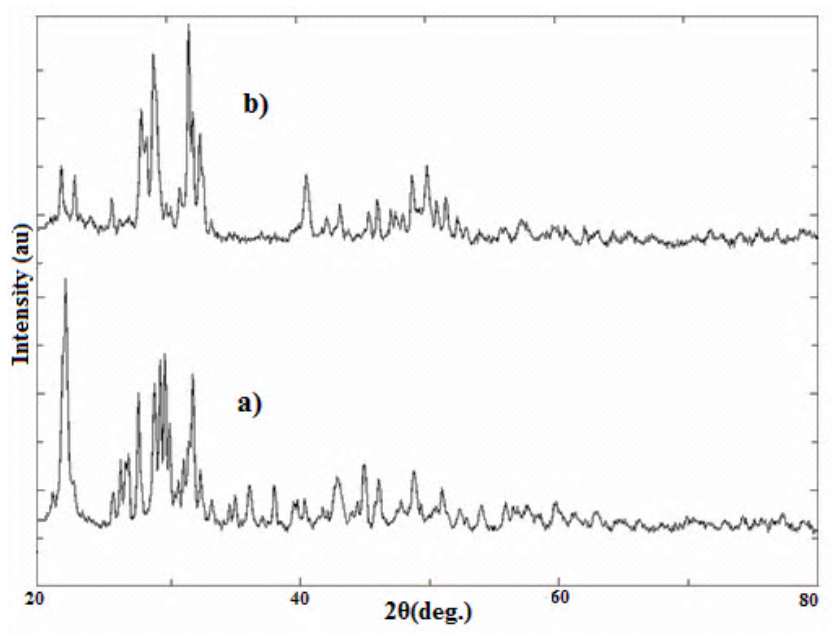

Fig. 1. XRD pattern of prepared samples with (a) lower and (b) higher concentrations of neodymia annealed at $1000{ }^{\circ} \mathrm{C}$ for $5 \mathrm{~h}$.

\section{Results and discussion}

\section{XRD studies}

The X-ray diffraction patterns of $\mathrm{Nd}$ doped silica annealed at $1000{ }^{\circ} \mathrm{C}$ for $5 \mathrm{~h}$ with (a) lower and (b) higher concentrations of neodymia are shown in Fig. 1. In case of first sample (a), the reflection peaks appeared at angles $2 \theta$ $21.8^{\circ}, 27.4^{\circ}, 28.7^{\circ}, 29.3^{\circ}, 31.2^{\circ}$. The size of nanocrystallites corresponding to these peaks may be calculated using well known Debye-Scherrer formula, $\mathrm{D}=\mathrm{k} \lambda / \beta \cos \theta_{\mathrm{B}}$, which is applicable only if stress related and instrumentation broadening are neglected. In our case, instrumentation broadening may be neglected while stress related broadening cannot be ignored. Taking into consideration the stress related broadening; we estimated $\beta_{\text {size }}$ (FWHM due to size effect) and $\beta_{\text {strain }}$ (FWHM due to strain) using Williamson-Hall method [26]. We used the relation $\beta_{\text {obs. }}=\beta_{\text {size }}+\beta_{\text {strain }}$ applicable in the absence of instrumentation broadening. The sharp peak centered at about $2 \theta \sim 21.8^{0}$ may be assigned to (100) phase of tetragonal crystoballite [JCPDS card 39-1425]. This phase indicates the presence of water molecules entrapped in the sample and the crystallite size is found to be about $31 \mathrm{~nm}$. The reflection peak at $27.4^{\circ}$ may be assigned to (010) phase of monoclinic $\mathrm{Nd}_{2} \mathrm{O}_{3}$ [JCPDS card 28-0671] and the size of nanocrystallites corresponding to this peak found to be $\sim 23.5 \mathrm{~nm}$. The peak at about $28.7^{\circ}$ may be due to the mixed phase of $\mathrm{Nd}-\mathrm{Si}$ compound (tetragonal $\alpha-\mathrm{Nd}_{2} \mathrm{Si}_{2} \mathrm{O}_{7}$ ) [27] with nanocrystallites size $\sim 26 \mathrm{~nm}$. The peak at about $29.3^{\circ}$ is due to $(\overline{4} 02)$ cubic phase of $\mathrm{Nd}_{2} \mathrm{O}_{3}$ [JCPDS card 
45-0087] with nanocrystallites size $\sim 38.2 \mathrm{~nm}$. The sharp reflection peak at $2 \theta \sim 31.2^{\circ}$, with size of nanocrystallites about $27.4 \mathrm{~nm}$, corresponds to the most intense reflection peak of neodymium oxide $\left(2 \theta=30.774^{\circ}\right.$, JCPDScard 43 1023). The peak at $44.5^{\circ}$ is ascribed to the formation of neodymium-silicon (Nd-Si) compound [28]. In case of second sample (b), reflection peaks have been observedat about $27.4^{\circ}, 28.7^{\circ}$ and $31.2^{\circ}$ which may be assigned to the same phases as discussed above, but the sizes of nanocrystallites corresponding to these peaks are found to be about $27,24.8$ and $39.1 \mathrm{~nm}$ respectively. In addition, peaks at about $40.5^{\circ}$ and $49.5^{\circ}$ have also been observed which may be due to $\mathrm{Nd}_{2} \mathrm{O}_{3}$ [29].

The XRD studies showed that, by increasing the heat treatment temperature the amorphous phase changed to $\alpha$ crystoballite phase (XRD patterns of samples annealed at temperature $800{ }^{\circ} \mathrm{C}(3 \mathrm{~h})$ and $900{ }^{\circ} \mathrm{C}(4 \mathrm{~h})$ are not shown here). It was found that, doping the sample with $\mathrm{Nd}^{3+}$ decreases the crystallite size of $\alpha$-crystoballite phase. On increasing the concentration of neodymia, the intensity of crystoballite peak at about $21.8^{\circ}, 44.5^{\circ}$ diminished to a large extent, while some other weak peaks of $\mathrm{Nd}_{2} \mathrm{O}_{3}$ also appeared. It is known that $\mathrm{Nd}^{3+}$ cation have a poor affinity for silica host matrices and easily tend to clusterize in the form of $\mathrm{Nd}_{2} \mathrm{O}_{3}$ precipitates. The appearance of the aggregates might be as a result of the low solubility of the neodymium in silica [30].The incorporation of a reasonable amount of neodymia in the silica network is sufficient to prevent the $\mathrm{SiO}_{2}$ crystallization. As the sharpness and intensity of peaks corresponding to neodymium silicate increases, the crystallinity of the sample increases with increase in dopant concentration.

\section{FTIR studies}

The infrared transmission spectra of the prepared samples provide some important information about the structural changes. Fig. 2 represents the structural evolution of samples annealed at $1000{ }^{\circ} \mathrm{C}$ for $5 \mathrm{~h}$ with different (a) lower, (b) higher concentrations of neodymia. FTIR spectra of sample (a) shows the emergence of absorption peaks centered at 3445.0, 2519.6, 1797.3, 1429.2, 1088.3, 946.4, $906.2,876.7,790.8,685.4,620.9,495.6,472.0 \mathrm{~cm}^{-1}$. A weak band observed at $3445.0 \mathrm{~cm}^{-1}$ is assigned to presence of water molecules [31]. The peaks observed at 2519.6 and $1797.3 \mathrm{~cm}^{-1}$ are unidentified/ undefined which disappeared in sample (b). A broad band at about $1429.2 \mathrm{~cm}^{-1}$ may be due to bending mode of $-\mathrm{OH}$ bond on plane. The peak around $1088.3 \mathrm{~cm}^{-1}$ corresponds to the TO vibrations mode of Si-O-Si asymmetric bond. ${ }^{[32]}$ The peaks at about 946.4 and $906.2 \mathrm{~cm}^{-1}$ is due to the asymmetric mode of Si-O-Nd bonds [3].The peak at $876.7 \mathrm{~cm}^{-1}$ is attributed to the formation of tetragonal A- $\mathrm{Nd}_{2} \mathrm{Si}_{2} \mathrm{O}_{7}$ [3]. The peak observed at $790.8 \mathrm{~cm}^{-1}$ is associated with symmetric $\mathrm{Si}-\mathrm{O}-\mathrm{Si}$ stretching or vibrational modes of ring structures [33]. The peaks at about 685.4 and $620.9 \mathrm{~cm}^{-1}$ are due to the presence of tetragonal A- $\mathrm{Nd}_{2} \mathrm{Si}_{2} \mathrm{O}_{7}$ and $\mathrm{I}_{-}-\mathrm{Nd}_{2} \mathrm{Si}_{2} \mathrm{O}_{7}{ }^{[3]}$ respectively. The peak around $472.0 \mathrm{~cm}^{-1}$ is due to bending mode vibrations of Si-O-Si [34].

In the FTIR spectra of sample (b), we observe absorption peaks appeared at 3605.5, 1431.7, 1106.5, $990.9,932.2,873.3,680.5,470.7 \mathrm{~cm}^{-1}$. A sharp peak observed at $3605.5 \mathrm{~cm}^{-1}$ is assigned to the stretching vibrations of $\mathrm{Si}-\mathrm{OH}$ bond [35]. A broad and weak peak observed at $1431.7 \mathrm{~cm}^{-1}$ may be due to the bending mode of $-\mathrm{OH}$ bond on plane. A peak appeared at $1106.5 \mathrm{~cm}^{-1}$ shows the presence of stretching vibrations of Si-O-Si bond [36]. The peak at about $990.9 \mathrm{~cm}^{-1}$ may be due to amorphous $\mathrm{SiO}_{2}$ [3] or may be due to stretching vibration mode of Si-OH bond. The peak at around $932.2 \mathrm{~cm}^{-1}$ appeared because of asymmetric mode of Si-O-Nd bonds vibrations [3]. The peaks at 873.3 and $680.5 \mathrm{~cm}^{-1}$ are attributed to the formation of tetragonal A- $\mathrm{Nd}_{2} \mathrm{Si}_{2} \mathrm{O}_{7}$ [3].The peak observed at $470.7 \mathrm{~cm}^{-1}$ is due to bending mode vibrations of Si-O-Si [33].

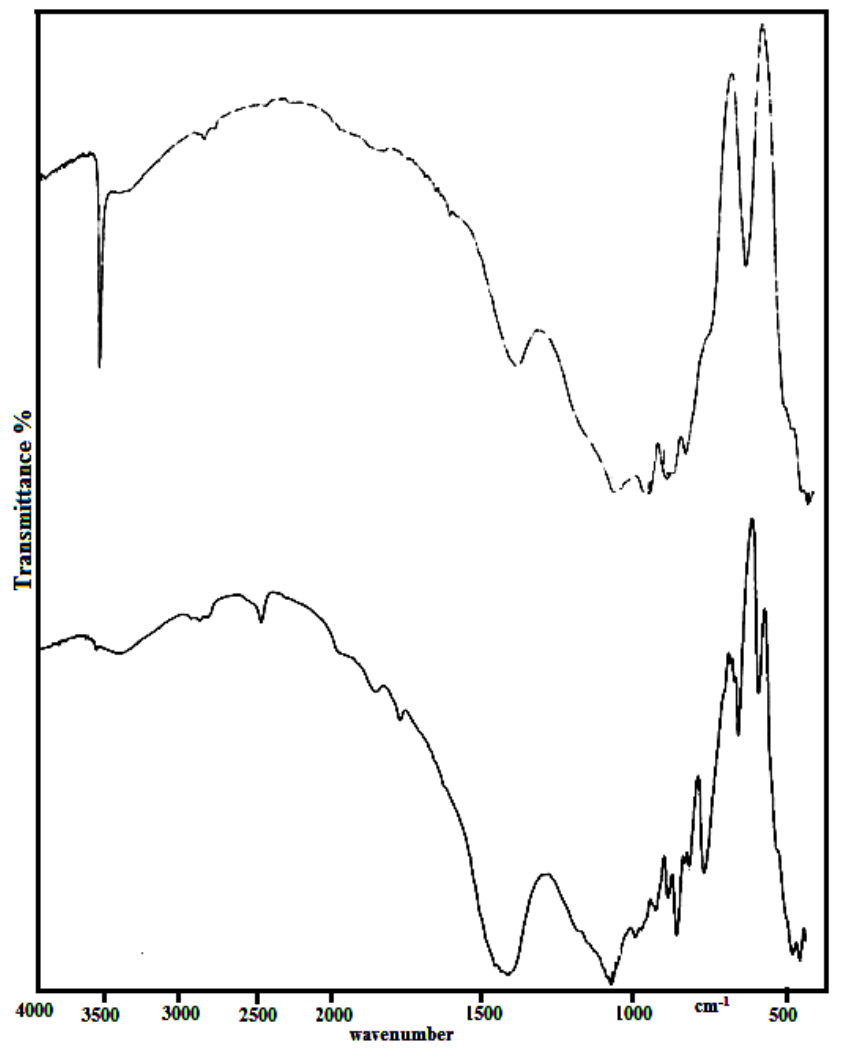

Fig. 2. FTIR spectra of prepared samples with (a) lower and (b) higher concentrations of neodymia annealed at $1000{ }^{\circ} \mathrm{C}$ for $5 \mathrm{~h}$.

On increasing the concentration of neodymia, stretching vibrations of $\mathrm{Si}-\mathrm{OH}$ bond appear prominently, the water molecules evaporates, the band at $1429.2 \mathrm{~cm}$ ${ }^{1}$ weakened. The peak at $790.8 \mathrm{~cm}^{-1}$ disappeared. The peaks at 685.4 and $620.9 \mathrm{~cm}^{-1}$ merged together and give a welldefined peak at $680.5 \mathrm{~cm}^{-1}$ which corresponds to tetragonal A- $\mathrm{Nd}_{2} \mathrm{Si}_{2} \mathrm{O}_{7}$. It has been observed that the peak at 1088.3 $\mathrm{cm}^{-1}$ is shifted towards higher wave number $\left(1106.5 \mathrm{~cm}^{-1}\right)$ as the doping concentration of dopant was increased which may be due to the densification of material. Also, Almeida et al. [37] explained the $1080 \mathrm{~cm}^{-1}$ position of Si-O-Si bonds in terms of strains in the Si-O-Si bridging bonds present at the surface of the pores. When densification proceeds pores collapse slowly, leading to strain relaxation and the band wave number increase. 


\section{TEM studies}

Transmission electron micrographs of Nd-doped silica with (a) lower and (b) higher dopant concentrations are shown in Fig.3.which depicts the micro-structural evolution of the sample. It shows that the neodymium oxide nanoparticles of size in the range from 26 to $35 \mathrm{~nm}$ are embedded in silica matrix. As the concentration of neodymia increases the crystallite size increases which is in agreement with the results of XRD.

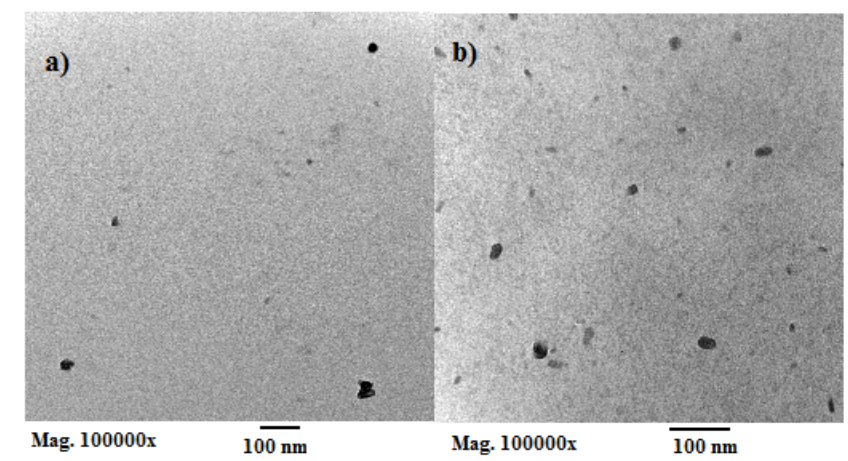

Fig. 3. TEM micrographs of prepared samples with (a) lower and (b) higher concentrations of neodymia annealed at $1000{ }^{\circ} \mathrm{C}$ for $5 \mathrm{~h}$.

\section{Conclusion}

The sol-gel method followed by heat-treatment has been employed to prepare Neodymia-doped silica glasses. XRD and TEM studies revealed that the neodymium ions aggregate inside the silica matrix and crystallize in the form of $\mathrm{Nd}_{2} \mathrm{O}_{3}$ nanocrystallites during glass sintering at high temperature $\left(1000{ }^{\circ} \mathrm{C}\right)$. From XRD results, it may be concluded that the particle size of crystoballite phase reduces from 26 to $24.8 \mathrm{~nm}$, while the particle size of $\mathrm{Nd}_{2} \mathrm{O}_{3}$ phase increases from 27.4 to $39.1 \mathrm{~nm}$, with increasing doping concentration. FTIR studies elucidate the bonding system of the constituent atoms and functional groups.

\section{Acknowledgement}

Authors gratefully acknowledge Sophisticated Analytical Instrumentation Facility (SAIF), Panjab University, Chandigarh for providing experimental facilities.

\section{Reference}

1. Cao, G. Nanostructured and Nanomaterials; Imperial College Press: London, 2004.

2. Kwaitkowski, K.C.; Lukehart, C.M. In Handbook of Nanostructured Materials and Nanotechnology; Nalwa, H.S (Ed.); Academic: New York, 2000.

3. Kepinski, L.; Wolcyrz, M.; Drozd, M. Mater. Chem. Phys. 2006, 96, 353.

4. Wang, L.; Zhang, L.; Fan, F.; Luo, J.; Zhang, P.; An, L. J. Am. Ceram. Soc. 2006, 89, 3570.

5. Zawadzki, M.; Kepinski, L. J. Alloys \&Compds. 2004, 380, 255

6. Singh, J.; Soni, N.C.; Srivastava, S.L. Bull. Mater. Sci. 2003, 26, 397.

7. Jiwei, Z.; Bo, S.; Xi, Y.; Liangying, Z. Ceram. Int. 2002, $28,737$.

8. Koechner, W. Solid State Laser Engineering, 4th ed., SpringerVerlag: Berlin, 1966.

9. Gan, F. Laser Materials; World Scientific: Singapore, 1994.

10. Kohli, J.T.; Shelby, J.E. Phys. Chem. Glasses 1991, 32, 67.

11. Shelby, J.E.; Kohli, J.T. J. Am. Ceram. Soc. 1990, 73, 39.

12. Lucas, L.; Chanthanasinh, M.; Poulain, M.; Brun, P.; Weber, M.J. J. Non-Cryst. Solids 1978, 27, 273.
13. Snitzer, E. Phys. Rev. Lett. 1961, 7, 444.

14. Weber, M.J. J. Non-Cryst. Solids 1990, 123, 208.

15. Mears, R.J. Electron Lett. 1985, 21,738.

16. Chakrabarti, S.; Sahu, J.; Chakraborty, M.; Acharya, H.N. J. NonCryst. Solids 1994, 180, 96.

17. Bentivegna, F.; Nyvit, M. J. Appl. Phys. 1990, 85, 2270.

18. Zeng, J.S.Q.; Greif, R. J. Mater. Res. 1996, 8, 687.

19. Kawaguchi, T.; Iura, J.; Taneda, N.; Hishikura, H.; Kokubu, Y. J. Non-Cryst. Solids 1986, 82, 50.

20. Beckers, J.V.L.; Leeuw, Sa.W.de. J. Non-Cryst. Solids 2000, 261, 87.

21. Zarzycki, J. J. Sol-Gel Sci. Technol. 1997, 8, 17.

22. Pope, E.J.A.; Mackenzie, D.J. J. Am. Ceram. Soc. 1993, 76, 1325.

23. Maniar, P.D.; Navrotsky, A.; Rabinovich, M.E.; Ying, Y.J.; Benziger, B.J. J. Non- Cryst. Solids 1990, 124, 101.

24. Sakka, S. J. Sol-Gel Sci. Technol. 1994, 3, 69.

25. Langlet, M.; Coutier, C.; Meffre, W.; Andier, M.; Fiek, J.; Rinet, R.; Jacquier, B. J. Lumin. 2006, 96, 295.

26. Williamson, G.K; Hall, W. ActaMetallurgica 1953, 1, 22.

27. Singh, J.; Soni, N.C.; Srivastava, S.L. Bull. Mater. Sci. 2003, $26,397$.

28. Wang, S.S.; Zhou, Y.; Lam, Y.L.; Kam, C.H.; Chan, Y.C.; Yao, X. Mat. Res. Innovat. 1997, 1, 92.

29. Kepinski, L.; Zawadzki, M.; Mista, W. J. Solid State Sci. 2004, 6, 1327.

30. Dimitriev, Y.; Bursukova, M.; Kashchieva, E.; Chernev, V.; Samuneva, B. J. Sol-Gel Sci. Technol. 1997, 8, 935.

31. Hammer, M.A.; Farneth, E.W.; Sun, Q. J. Am. Chem. Soc. 1996, 118, 7708 .

32. Ono, H.; Katsumata, T. Appl. Phys. Lett. 2001, 78, 1832.

33. Battisha, I.K. Egypt. J. Sol. 2001, 24, 51.

34. Brinker, C.J.; Tallant, D.R. ; Roth, E.P.; Asley, C.S. J. Non-Cryst. Solids 1986, 82, 117.

35. Tatzber, M.; Stemmer, M.; Spigel, H.; Katzlberger, C.; Haberhauer, G.; Gerzabek, M.H. Environ. Chem. Lett. 2007, 5, 9.

36. Yamane, M.; Kojima, T. J. Non-Cryst. Solids 1981, 44, 181.

37. Almeida, R.M.; Guiton, T.A.; Pantano, C.G. J. Non-Cryst. Solids 1990, 121, 193 